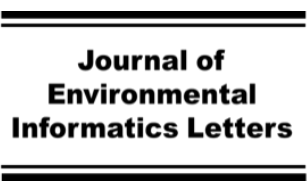

WwW.iseis.org/jeil

\title{
Assessing the Impact of Urban Form on the Greenhouse Gas Emissions from Household Vehicles: A Review
}

\author{
X. L. $\operatorname{Tian}^{1}$, C. J. $A n^{1 *}$, and Z. K. Chen ${ }^{1}$ \\ ${ }^{1}$ Department of Building, Civil and Environmental Engineering, Concordia University, Montreal, QC H3G 1M8, Canada
}

Received 31 April 2020; revised 29 May 2020; accepted 15 June 2020; published online 30 June 2020

\begin{abstract}
Urban growth is associated with a number of environmental issues. One of the most serious environmental concerns is the air pollutants and increasing greenhouse gas (GHG) emissions. This study presents a comprehensive review of the impact of urban form on the GHG emissions from household vehicles. A comparative study encompassing the methods used for identifying the relationship between urban form and vehicle GHG emissions was conducted. Household vehicle GHG emissions in different urban forms were investigated, drawing upon various existing studies. The internal variables that define urban form, such as density, connectivity, land use mix, and accessibility, were further discussed with respect to their degree of influence on household vehicle GHG emissions. Finally, a discussion of opportunities in urban form which may be conducive to household vehicle GHG emission mitigation in the long term was presented.
\end{abstract}

Keywords: urban form, GHG emissions, household vehicles, urban planning

\section{Introduction}

Urban growth, especially the conversion of land to urban uses, is associated with a number of environmental issues. One of the most serious environmental concerns is the increasing greenhouse gas (GHG) emissions (Zhang et al., 2019; Cai et al., 2020; Chen et al., 2020; $\mathrm{Hu}$ and Xia, 2020). According to previous studies, the relationship between urban form and GHG emissions is highly complex. It directly or indirectly contributes to GHG emissions from multiple perspectives and the impact has been shown to be significant (Sun et al., 2014; Fang et al., 2015; Song et al., 2019). In this context, urban form refers to the spatial organization and functional units of a city. It reflects the growth and expansion of cities, as well as the history of human activity in that location. The classification of urban form is expressed in a broad array in the literature. The compact city and dispersed city are widely recognized as the major poles in this range, while other classifications, such as monocentric city and polycentric city, are found closer to the middle of the range (Tsai, 2005). A considerable amount of research has been carried out examining the relationship between the spatial allocation of urban development and the associated environmental issues, especially GHG emissions. Ishii et al. (2010) for instance, tested energy-saving technologies such as photovoltaic cells and combined heat and power (CHP) in three urban forms as predicted in scenarios for the years 2030 and 2050. In terms

\footnotetext{
* Corresponding author. Tel.: +1-514-848-2424

E-mail address: chunjiang.an@ concordia.ca (C.J. An).
}

ISSN: 2663-6859 print/2663-6867 online

(C) 2020 ISEIS All rights reserved. doi:10.3808/jeil.202000029. of the benefits of both photovoltaic cells and CHP, their results showed that medium density typically outperforms the highdensity centralized and low-density decentralized forms (Ishii et al., 2010). On the other hand, other researchers have noted that lower density in residential settings gives rise to more heat island formation than higher density, as it brings about more radiant heat energy (Yao et al., 2020). As such, policy makers should consider compact moderate-to-high-density residential development patterns for reducing emission of radiant heat energy (Stone and Rodgers, 2001).

A wide range of research has been conducted to study GHG emissions from residential sources such as space heating and household electricity use in the context of different patterns of urban development (Glaeser and Kahn, 2010). In has been found that, besides these sources, GHG emissions is largely caused by people commuting to and from work (Legras and Cavailhès, 2016). According to the Energy Information Administration, the state average transportation sector share of energy-related $\mathrm{CO}_{2}$ emissions is $36.7 \%$, representing the largest proportion among the commercial, electric power, residential, industrial, and transportation sectors. Although fuel efficiency has improved, this is still more than offset by the effect of increases in total travel and freight movement, which is expected to lead to transportation energy consumption peaking in 2020 (U.S. Energy Information Administration, 2019). It should be noted there are many important factors affecting household commuting behaviour, particularly the spatial evolution of urban development (Hawkes, 2014). Although the transformation of urban form has a limited effect in terms of influencing GHG emissions in the short term, (due to the considerable amount of time required to build up the supporting infrastructure), it can 


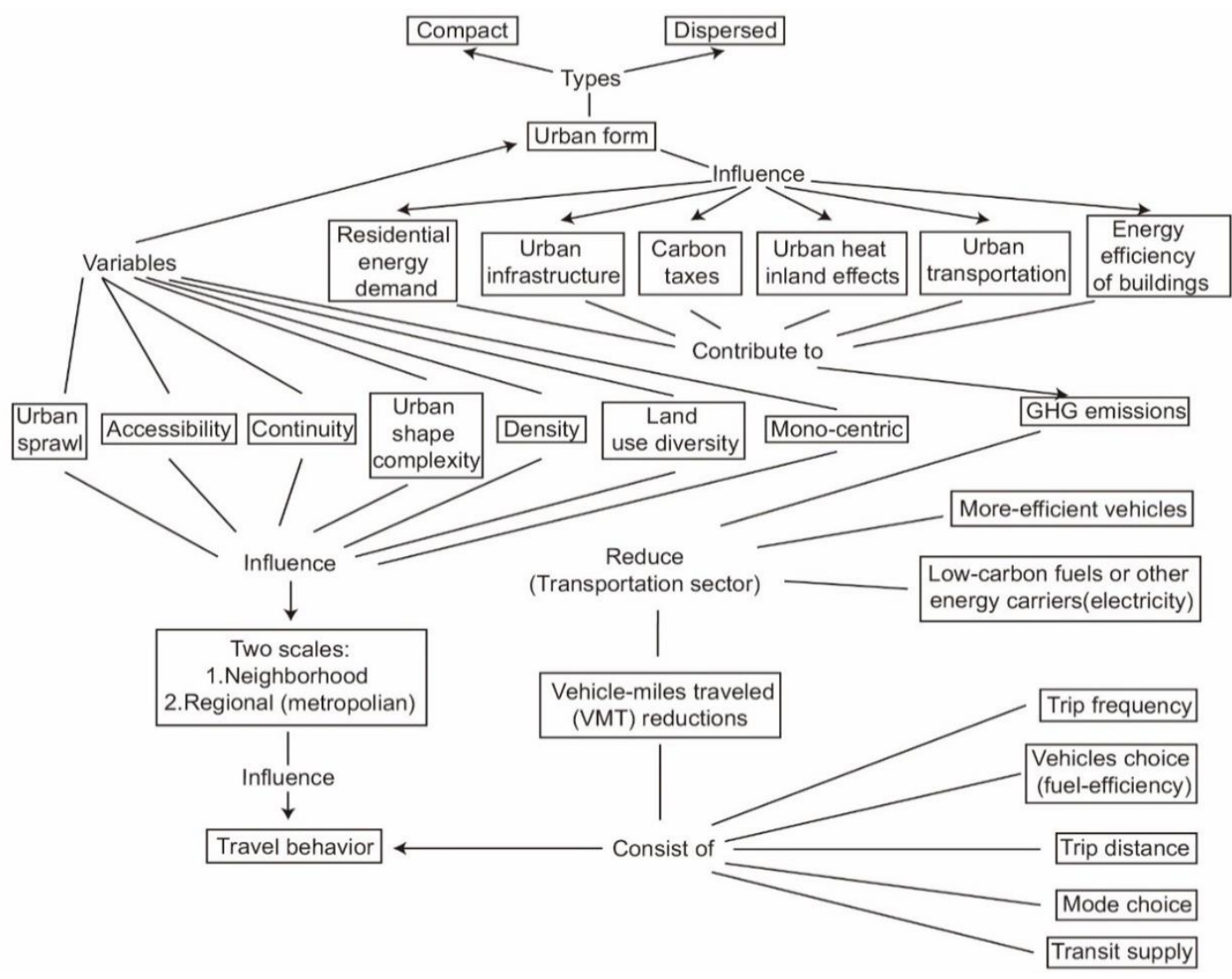

Figure 1. Concept map of relationship between urban form and vehicle GHG emission.

be very efficacious in the long run. Therefore, it is important to understand how urban development, and the variables underlying different urban forms, affect household commuting behaviour and, ultimately, the mitigation of vehicle GHG emissions at the household level.

To better understand the role of sustainable urban development in GHG mitigation, in recent years a number of scholars have studied the influence of urban form on individual household $\mathrm{CO}_{2}$ emissions. Dulal et al. (2011) examined the empirical and theoretical evidence linking land-use policy to transport emissions and investigated the impact of residential and employment density on travel demand. Anderson et al. (1996), meanwhile, targeted urban transport energy use in order to evaluate the current state of integrated urban form models and energy utilization in the environment.

This study presents a comprehensive review of the impact of urban form on the GHG emissions from household vehicles. The introduction is followed by a comparative study encompassing the methods used for identifying the relationship between urban form and vehicle GHG emissions. Household vehicle GHG emissions in different urban forms are then investigated, drawing upon various existing studies for discussion purposes. In the next section, the internal variables that define urban form, such as density, connectivity, land use mix, and accessibility, are discussed with respect to their degree of influence on household vehicle GHG emissions. Finally, a discus- sion of opportunities in urban form which may be conducive to household vehicle GHG emission mitigation in the long term is presented.

\section{Methods Used for Identifying the Relationship between Urban Form and Vehicle GHG Emissions}

\subsection{Panel Data Analysis}

Panel data, also known as longitudinal or cross-sectional time-series data, are a dataset in which the behaviour of entities is observed across time. Corresponding to panel data are crosssectional data and time series data. Cross-sectional data are a collection of observations for multiple subjects at a single point in time, which means it is a one-time survey with no relation to time. Time series data, meanwhile, are a collection of observations for a single subject at different time intervals. It reflects the state of degree of change of a thing or phenomenon over time. Panel data are usually collected over time and for different individuals, and then a regression is run over these two dimensions (Figure 2). In this respect, the notable feature of panel data is that the sample has time continuity. As a result, the cost of collecting panel data is usually high and the data are not easy to obtain, although such data are widely used in social science, epidemiology, and econometrics to examine underlying influencing factors. The use in these fields is due to the characteristics of high degree of freedom and less multicollinearity, hence, 
which can improve the efficiency of estimation. There are two types of panel data models, the unobserved effect model and the pooled regression model. Usually there are unobservable variables affecting urban form, so the unobserved effect model is applied in this field of study as a way of characterizing relationships.

The unobserved effect model can be further divided into the fixed effect (FE) model, the random effect (RE) model, and the mixed effect (ME) model. The FE model is used to study only the internal variation of sample data with time (i.e., changes in the same sample data at different time points), while it does not consider the variation between different data (i.e., heterogeneity). It can effectively eliminate time-invariant factors and tends to make the results more accurate. As such it is proven to be a superior option when studying individuals as the whole study population. Many scholars have used the FE model to analyze the factors that influence GHG emissions.

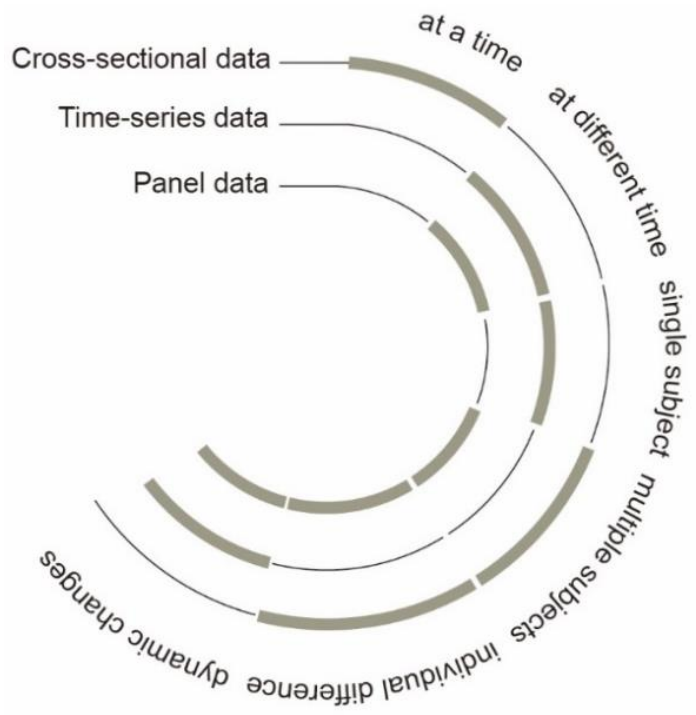

Figure 2. Comparison among three kinds of data.

In common research procedures, a panel unit root test is needed for testing the stationarity of the variables. Fang et al. (2012) and Yang (2015) both employed the Levin-Lin-Chu (LLC) unit root test for the common unit root that is identical among cross-sections. They were subsequently able to use the panel model to study the major determinants of $\mathrm{CO}_{2}$ emissions, such as GDP, total trade, foreign direct investment net inflows, and total energy consumption. Al-mulali (2012) reviewed the advantages of panel data, noting that it is capable of considering time sequence factors in characterizing the relationships among different variables while excluding the inversion between cause and effect. They further noted that it is capable of discovering dynamic trends, and of eliminating interference factors in determining the causality. Fang et al. (2015) used the panel data method to quantify the effect of the changing urban forms of thirty provincial capital cities in China on $\mathrm{CO}_{2}$ emissions from 1991 to 2011 . To obtain the estimated $\mathrm{CO}_{2}$ emissions, the energy-related statistical data, including fossil fuels,
$\mathrm{CO}_{2}$ emission coefficient, and low calorific value, were used. They also employed ten pattern variables to describe the change of urban form: total area (TA), largest patch index (LPI), areaweighted mean shape index (AWMSI), area-weighted mean patch fractal dimension index (AWMPFDI), perimeter area ratio distribution (PARA_MN), percentage of like adjacencies (PLADJ), patch cohesion index (COHE-SION), aggregation index (AI), landscape shape index (LSI), and contiguity (CONTIG). The specific equation for Fang's panel data model was: $\mathrm{CE}_{i t}=\beta_{i}+\mathrm{Z}_{i t} \varphi+\mu_{i}+\varepsilon_{i t}$, where $\mathrm{CE}_{i t}$ is the $\mathrm{CO}_{2}$ emission of city $i$ in year $t, \beta_{i}$ is the scalar coefficient, $\varphi$ is the vector of parameters, $\varepsilon_{i t}$ is the random error, and $\mathrm{Z}_{i t}$ is the pattern metrics to describe the change of urban form. Ten regression models were separated by the explanatory variables to estimate the relationship between $\mathrm{CO}_{2}$ emissions and urban form. The criteria for choosing panel data analysis, it should be noted, are with low correlation among variables and low multi-collinearity among all regression models. After the operation, TA, COHESION, AI CONTIG, AWMSI, AWMPFD, and LSI all showed statistical significance.

Yang et al. (2015) dealt with the quantification of direct $\mathrm{CO}_{2}$ emissions in the same manner as Fang had for the transportation sector. In addition to direct emissions, the indirect emissions of $\mathrm{CO}_{2}$ from heat and electricity consumed in the transportation sector were also included. Seven factors representing socio-economic, urban form, and transportation were chosen as the independent variables, while average city size (ACS), urban population density (UPD), and urban road density (URD) were the key metrics of urban form employed. The method they used for calculating URD was to divide the total length of urban roads by the total developed area of the city. Besides the LLC unit root, the Augmented Dickey-Fuller (ADF) was employed for the assumption of individual unit root.

In addition to using panel data to directly estimate the relationship between urban form and GHG emissions, the same method can also be used to study the relationship between urban form and vehicle-miles travelled (VMT), which also indirectly affects GHG emissions. Su (2010) collected the panel data from 85 urban areas in the United States and applied a system, dynamic panel data (DPD) estimation, to estimate the model. The core of the mixed-effect model $\mathrm{Su}$ proposed is to divide the variation of each variable into individual and intraindividual variations, then show the relationship between these and the dependent variables. The mixed-effect model not only can study the internal differences between individual variables and dependent variables and thereby avoid the interference of missing variables, but also can examine the influence of fixed time factors on dependent variables through the differences between individuals. A notable innovation of Su's work is that it employed a Hausman test to prove the correlation between the individual effects and the explanatory variables, justifying the use of the system DPD estimation. In this dynamic demand equation, the VMT per capita is influenced by real gasoline price, real household income, urban spatial characteristics such as urban area size, road density, population density, peak per freeway lane-mile, city age, heavy rail and light rail availability, and transit passenger miles per capita. 
Table 1. Comparison among Analysis Methods

\begin{tabular}{lll}
\hline Analysis method & Relationship among variables & Characteristic \\
\hline $\begin{array}{l}\text { Linear correlation } \\
\text { analysis }\end{array}$ & Equal, random & Cannot reflect the causal relationship between indexes \\
$\begin{array}{l}\text { Linear regression } \\
\text { analysis }\end{array}$ & $\begin{array}{l}\text { Dependent variables and independent } \\
\text { variables, can be measured directly }\end{array}$ & $\begin{array}{l}\text { Can provide direct effects } \\
\text { Cannot show possible indirect effects } \\
\text { Cannot explain the multicollinearlity between indexes }\end{array}$ \\
$\begin{array}{l}\text { Structural equation } \\
\text { model analysis }\end{array}$ & $\begin{array}{l}\text { Latent variables and observable explicit } \\
\text { variables }\end{array}$ & $\begin{array}{l}\text { Can process multiple dependent variables } \\
\text { Can analyze the effect of individual indicators on the whole and the } \\
\text { relationship between individual indicators }\end{array}$ \\
\hline
\end{tabular}

Barla et al. (2011) examined the influence of land use and transit supply characteristics on the GHG emissions from urban transportation, with the characteristics of individual and household taken into account as the determinants. They took Québec City as an example to apply an activity-based longitudinal panel survey which involved information about household activities and trip data from 400 respondents belonging to 250 households. In their study, the amount of GHG emission was divided into two distinct emitting modes: private vehicles (PV) and public buses (B). The estimated calculation of PV referred to the average fuel consumption rate of vehicles, the average speed correction factor, the estimated distance in the trip, the emission factor, and the number of passengers in the vehicles. The calculation of GHG emissions for public bus involved the fuel consumption rate (58.9 litres of diesel per $100 \mathrm{~km}$ ), the estimated distance, the emission factors for bus transit, and the average number of passengers on board during peak and offpeak periods. The city was characterized into four areas based on the historical development, the center, the old suburbs, the new suburbs, and the periphery, while the land use patterns in these four zones were described in terms of residential density and job density. The results showed $1.2 \%$ reduction in travel emissions of a given resident was to move to a neighbourhood that is $10 \%$ denser. In terms of transit supply, they found that a reduction in bus travel time would be more effective in reducing travel-related GHG emissions.

\subsection{Structural Equation Modelling}

Structural Equation Modelling (SEM) is a method for establishing, estimating, and testing causal relationship models that consists of a measurement model and a structural model. Measurement models are used to describe the relationship between indicators and latent variables, while structural models are used to describe the relationships among various latent variables. In general, the relationship among latent variables is also shown in the structural model, and this is typically the focus of the given study. The entire data analysis process of SEM is often used in the fields of economics, social science, management, and psychological research. In a model of this nature, both observable explicit variables and latent variables that cannot be directly observed may exist. Traditional statistical analysis methods cannot properly accommodate these latent variables, whereas SEM can replace multiple regression, path analysis, factor analysis, and covariance analysis to clearly analyze the effects of individual indicators on latent variables and the interactions between individual indicator relationship by calculating direct effects, indirect effects, and total effects. Total effect refers to the sum of direct effects and indirect effects. A comparison among three analysis methods, linear correlation analysis, linear regression analysis, and SEM, was described in a previous study of Kaplan (1995) (Table 1).

Liu and Shen (2011) examined the effects of urban land use characteristics on household travel and transportation energy consumption, and applied SEM to model the linkage between urban form and household transportation energy consumption in the Baltimore metropolitan area. The vehicle characteristics, including type, vehicle age, VMT, and energy consumption, were collected from National Household Travel Survey (NHTS) data. In terms of urban form, density, design, land use mix, and accessibility were considered as the primary dimensions used for testing its influence on travel. In their research, the multivariate regression model was used to examine the relationships among urban form characteristics (density, land use mix, street design and accessibility), household socioeconomic characteristics, vehicle characteristics, and household annual VMT. The results showed that the most significant variable in urban form is accessibility. However, in reality, separate single regressions are unable to analyze the complex relationships existing among urban form variables, VMT, energy consumption, and vehicle characteristics. In their SEM, the endogenous variables included VMT, vehicle gasoline consumption, and vehicle characteristics, while characteristics such as travel mode, vehicle type, and speed were considered as intermediate variables. The structural coefficient, it should be noted, is the direct effect of a variable, while the mechanism of indirect effect is that it is exerted through one or more endogenous variables. It was found that urban form had total effects rather than direct effects on VMT, which means urban form may influence the travel speed primarily and thus indirectly influence VMT. Moreover, they found that denser form had both direct and total effects on the travel mode, especially for inducing walking as a travel mode choice.

Lee and Lee (2014) used multilevel SEM based on weighted least squares estimation in conjunction with the missing variable method to examine the relationships between total household $\mathrm{CO}_{2}$ emissions from transportation and residence and multiple endogenous variables. Multilevel SEM is a combination of multilevel linear modelling and conventional SEM. When analyzing the data, it can moderate bias and enhance statistical power (Preacher et al., 2011). Due to the limited data available 
for their study, the $\mathrm{CO}_{2}$ emissions from household travel in independent models were analyzed. Two endogenous variables considered were VMT and $\mathrm{CO}_{2}$ emissions in the transportation sector, while the predictors with regard to urban spatial structure variables involved population density, population centrality and polycentricity. The way they estimated the $\mathrm{CO}_{2}$ emissions from household driving was by using the annual VMT, MPG variables, and emissions factor, then calculating the annual gasoline consumption of each vehicle and the associated $\mathrm{CO}_{2}$ emissions. They found that the amount of carbon emissions from the transportation sector is more dependent on urban form variables when compared to the residential sector.

Compared with other data analysis modelling methods, SEM has three advantages. First, unlike regression analysis, SEM can handle multiple dependent variables simultaneously. Second, it can better sustain measurement errors in the independent and dependent variables than can other methods. Third, considering that the existing relationships between latent variables and their structures in the same study will influence each other, SEM can simultaneously estimate the structure of a single latent variable and the relationships among all latent variables. Fourth, while traditional factor analysis is challenged to deal with an indicator that belongs to multiple factors or with models containing higher-order factors, SEM can accommodate more flexible measurement models. Finally, SEM has the advantage of being capable of estimating how well the entire model fits.

\subsection{Other Methods}

The above two models are suitable for research with many variables and complex relationships, especially those with large time spans and indirect effects. In addition to these two models, in the field of carbon emissions and urban form structures, when the research variables are not complicated, direct linear regression can also be used. A number of past studies have, after defining the dependent and independent variables, applied direct linear regression methods to prove the existence of causality.

For instance, Zahabi et al. (2012) used Montréal as a case study, drawing upon neighbourhood typologies to estimate the relationships among urban form, transit accessibility, and emerging green technologies, seeking to ascertain the impact on GHG emissions amount at the trip level for the year 2003. For calculating the amount of GHG emissions, private motor vehicles and public transit were distinguished as the two emitting mode categories. With regard to private motor vehicle trips, the emissions were evaluated based on distance and average speed at the link level, vehicle fuel consumption rate, and emission factors. In terms of urban form and transit accessibility, there were three indicators taken into account: residential density, land use mix, and transit accessibility. An approach employing a nine-cell grid with $500 \mathrm{~m}$ sides was applied to the city's metropolitan area, creating a buffer of $900 \mathrm{~m}$ radius. After measuring these three indicators, neighbourhood typologies were created accordingly. In order to test the impact of UF and TS on GHGs, an OLS regression was carried out in which the population density, land use mix, and transit accessibility were entered into the model. It was integrated with a simultaneous equation model, and then the neighbourhood typology choices were modelled as simultaneous outcome choices. Finally, the grid cells with households were classified into five clusters using K-means statistical cluster analysis. The results showed that as the population density, transit accessibility, and land use mix index decrease from the central neighbourhoods to the suburbs, the GHG footprint per household will increase correspondingly.

Bereitschaft and Debbage (2013) applied existing sprawl indices and spatial metrics to quantify urban form, and used a series of linear regression models to assess the relationship between air pollution (dependent variables) and various variables in urban form and urban sprawl (independent variables). The data used in their air mitigation measurement were the nonpoint source emission of the precursor nitrogen oxides and volatile organic compounds (VOCs), the concentration and the nonpoint source emission of the ozone and fine particulate matter (PM2.5), as well as the emission of $\mathrm{CO}_{2}$ from on-road sources. The different sprawl indices were used for reference on the basis of residential density, land use mix, street accessibility, and degree of centering, which are the main components of urban form. Furthermore, urban continuity and urban shape complexity were considered as variables to expand the potential connections between urban form and air pollution. In sixty linear regression models, each model included one or more measurements of urban form/urban sprawl, and combined four or five related control variables as independent variables. Six variables, temperature, moisture, average annual wind speed, metropolitan population, regional population within $500 \mathrm{~km}$, and metropolitan land area, were incorporated as the indirect influencing indicators. Their results showed that increasing continuity could reduce the VOC emissions while increasing urban shape complexity could contribute to NOx emissions and annual PM2.5. Moreover, the urban sprawl indices were proven to have a significant influence on air pollution, while only the residential density was found to have a significant impact on on-road source $\mathrm{CO}_{2}$ emissions.

Makido et al. (2012) carried out correlation analyses to research the relationship between urban form and $\mathrm{CO}_{2}$ emissions after applying remote sensing in fifty cities in Japan with similar socio-economic characteristics to consider the physical attributes for developing spatial indices of urban form. In their spatial metrics, compactness index (CI) and compactness index of the largest patch (CILP) were the two indicators of compactness, while area weighted mean shape index (AWMSI) and area weighted mean patch fractal dimension (AWMPFD) represented complexity. A higher $\mathrm{CI}$ is indicative of less fragmentation and larger urban settlement patches, further indicating a regular "shape" and a lower "number" of patches. CILP, meanwhile, expresses the overall shape of an urban center, while AWMSI represents the irregularities and complexities in the shape of a given patch. AWMPFD was introduced as a way of describing the granulation of shapes. The buffer compactness index (BCI) was also considered in their study as a means of indicating the distance and density of a city sprawled between central business areas and suburban areas, where 
Table 2. Published Studies about Urban Form Variables and Pollutant Variables Adapted by Bereitschaft and Debbage (2013)

\begin{tabular}{|c|c|c|c|}
\hline Scale & Pollutant variables & Urban form variables & References \\
\hline $\begin{array}{l}83 \text { U.S. PMSAs (primary } \\
\text { metropolitan statistical area) }\end{array}$ & $\mathrm{O}_{3}$ concentration & $\begin{array}{l}\text { Residential density, centrality, mix of uses, } \\
\text { street connectivity }\end{array}$ & Ewing et al. (2002) \\
\hline $\begin{array}{l}45 \text { U.S. MSAs (metropolitan } \\
\text { statistical area); PMSAs }\end{array}$ & $\begin{array}{l}\mathrm{O}_{3} \text { exceedance, } \mathrm{VOC}, \\
\text { NOx emissions }\end{array}$ & $\begin{array}{l}\text { SGA sprawl index, residential density, } \\
\text { centrality, mix of uses, street connectivity }\end{array}$ & Stone Jr (2008) \\
\hline $\begin{array}{l}80 \text { U.S. "regions" (associated } \\
\text { with SGA index PMSAs) }\end{array}$ & $\begin{array}{l}\mathrm{O}_{3} \text { concentration, } \\
\text { exposures; } \mathrm{PM} 2.5 \\
\text { concentration, } \\
\text { exposures }\end{array}$ & SGA sprawl index & Schweitzer and Zhou (2010) \\
\hline 83 global cities MSA scale & $\mathrm{NO}_{2}$ concentration & Compactness and contiguity of development & Bechle et al. (2011) \\
\hline 111 U.S. urban areas & $\begin{array}{l}\mathrm{O}_{3} \text { exposure, } \mathrm{PM} 2.5 \\
\text { exposure, } \mathrm{LAQI}\end{array}$ & $\begin{array}{l}\text { City shape, jobs-housing imbalance, population } \\
\text { centrality, population density, road density, } \\
\text { transit supply }\end{array}$ & Clark et al. (2011) \\
\hline $\begin{array}{l}30 \text { provincial capital cities in } \\
\text { China }\end{array}$ & $\mathrm{CO}_{2}$ emissions & $\begin{array}{l}\text { TA, LPI, AWMSI, AWMPFDI, PARA_MN, } \\
\text { PLADJ, COHESION, AI, LSI, CONTIG }\end{array}$ & Fang et al. (2015) \\
\hline $\begin{array}{l}33 \text { provincial capital cities in } \\
\text { China }\end{array}$ & $\mathrm{CO}_{2}$ emissions & $\begin{array}{l}\text { Average city size, urban population density, } \\
\text { urban road density, per capita GDP, per capita } \\
\text { disposable income of urban households }\end{array}$ & Yang et al. (2015) \\
\hline Household level & $\mathrm{CO}_{2}$ emissions & $\begin{array}{l}\text { Gender, university diploma, age group, } \\
\text { household size, employment status, income } \\
\text { group, residential zone }\end{array}$ & Barla et al. (2011) \\
\hline Household level & $\mathrm{CO}_{2}$ emissions & $\begin{array}{l}\text { Population density, population centrality, } \\
\text { polycentricity }\end{array}$ & Lee and Lee (2014) \\
\hline City level-Montreal & $\mathrm{CO}_{2}$ emissions & $\begin{array}{l}\text { Residential density, land use mix, transit } \\
\text { accessibility }\end{array}$ & Zahabi et al. (2012) \\
\hline 86 U.S. metropolitan areas & $\begin{array}{l}\text { NOx emissions, VOC, } \\
\text { PM2.5, } \mathrm{CO}_{2} \text { emissions }\end{array}$ & $\begin{array}{l}\text { Residential density, land use mix, street } \\
\text { accessibility, degree of centering, urban } \\
\text { continuity, urban shape complexity }\end{array}$ & $\begin{array}{l}\text { Bereitschaft and Debbage } \\
(2013)\end{array}$ \\
\hline 50 cities in Japan & $\mathrm{CO}_{2}$ emissions & CI, CILP, AWMSI, AWMPFD, BCI) & Makido et al. (2012) \\
\hline 142 U.S. cities & $\mathrm{CO}_{2}$ emissions & $\begin{array}{l}\text { Population amount, area, population density, } \\
\text { linear population density }\end{array}$ & Hankey and Marshall (2010) \\
\hline Municipality level & $\mathrm{CO}_{2}$ emissions & $\begin{array}{l}\text { Infill, Constant Density and Suburban Nation } \\
\text { population distribution }\end{array}$ & Matsuhashi and Ariga (2016) \\
\hline
\end{tabular}

a high degree of compactness and monocentricity is associated with a larger BCI value. Among the six dependent variables, industrial sector, commercial sector, residential sector, transportation sector, passenger transport, and freight transport, only the residential and passenger transport sectors were found to have relatively high correlation with the spatial metrics.

Hankey and Marshall (2010) developed six scenarios for high and low sprawl in urban growth in the United States, applying a Monte Carlo approach and employing three vehicle and fuel technology scenarios to estimate the total passenger vehicle kilometers travelled (VKT) and resulting GHG emission for US urban areas in the future. Based on the urban growth patterns in 142 US cities during the period 1950 to 2000 , they predicted six scenarios: three scenarios corresponding to the smallest, average, and largest decadal changes in population density from 1950 to 2000 , and three bounding scenarios, which were Infill Only, Constant Density, and Suburban Nation. They used four parameters, population, area, population density, and linear population density, to capture the growth scenarios by generating Monte Carlo statistical distributions. The total VKT was predicted based on the population and population density, and then the passenger vehicle GHG emissions were calculated based on the technology scenarios. In their Monte Carlo method, the population distribution, the population/area correlation and the VKT population-density correlation were the three input parameters used for the scenarios for the year 2020. In terms of the technology scenarios, it involved vehicles and fuels. They proposed three possibilities which could influence fuel carbon content and vehicle efficiency for the future. The first was a base case technology scenario which assumes gasoline will still be the mostly widely used fuel in the future, with a stable life cycle assessment emissions factor. The second technology scenario involved a combination of gasoline from tar sands and coal-to-liquid technology replacing conventional gasoline. The third included fuel-efficient light duty vehicles, such as hybrid electric vehicles as the most widely used vehicle on the road. The results pointed to a high likelihood that increasing annual VKT will more than offset any progress in vehicle and fuel technology if urban form development modes are overlooked.

Matsuhashi and Ariga (2016) determined the correlation between past municipal population distribution and passenger car $\mathrm{CO}_{2}$ emissions in Japan for the period 1980 to 2005, and then simulated the emissions in 2030 under both compact and dispersed scenarios. In the first step, a regression analysis was employed to analyze the relationships between the population 
distribution and the $\mathrm{CO}_{2}$ emissions from passenger cars. The results were also used for the subsequent scenario analysis. The total annual emissions were calculated as the aggregation of emissions by weekday and non-weekday, municipality and vehicle type. Other factors needed for the calculation included the emission factor, travel distance per trip, vehicle registration, and the number of trips. The vehicle types considered in determining the emission factor included mini cars, small cars, buses, mini freight vehicles, light duty vehicles, passengerfreight vehicles, heavy duty vehicles, and specific purpose vehicles. With regard to the population distribution, a tertiary mesh was created to divide the country into a grid of $1 \mathrm{~km} \times 1$ $\mathrm{km}$ mesh cells. Through the cohort change ratio method, future scenarios were constructed based on the opposite patterns of population distribution changes recently observed. The results showed that the difference in emissions per capita between the compact and dispersed scenarios is roughly 5\% in Japanese municipalities as a whole. Finally, Bereitschaft and Debbage (2013) conducted a review of prior studies evaluating the direct associations between variables in urban form and air pollutions, where a number of related studies focusing on the direct relationship between the variables and GHG emissions were also incorporated into their review (Table 2).

\section{Household Vehicle GHG Emissions in Different Urban Forms}

\subsection{Dispersed City}

The distinguishing features of a dispersed city are low residential density, low accessibility for newly built settlements, and a central business district with a small concentration of population and employment (Muñiz et al., 2006). Among the wide range of factors that have accelerated new housing construction and urban dispersion in recent decades, the mass diffusion of cars is one of the most influential factors. Furthermore, the cost for constructing new settlements in suburban areas is much lower than that in the historic center as the revitalization of mature areas is costly (Balsas, 2000). In addition to these economic considerations, political factors may also be key determinants of urban development patterns. The high degree of administrative fragmentation and local autonomy may cause unfair financial competition in the process of attracting land investment, which will lead to decentralized urban development (Carruthers, 2003).

Urban dispersion can bring about two groups of environmental implications. The first is the direct environmental costs resulting from scattered development of new housing. Contrary to the compact pattern of development, isolated housing patterns lead to more waterproof land and water consumption. It also entails the loss of rich soil, and a higher degree of land fragmentation and homogeneous land use patterns. The second group of effects has to do with the pattern of commuting in dispersed urban areas. The associated effects on the environment include noise and air pollution, land occupancy, and traffic accidents. Urban dispersion uses up land that would otherwise be available for ecological uses, while the excessive energy consumption leads to air pollution, exhaustion of non-renewable energy, and gas emissions, which ultimately contribute to climate change (Anderson et al., 1996; Wu and Xia, 2019; Chen et al., 2020; Liu et al., 2020).

Ewing and Rong (2008) conducted a study investigating the relationship between the choice of housing type and urban form, and found that multifamily housing is seven time less popular in dispersed areas than in compact areas. With their study combining path analysis, they concluded that residential energy use will be higher in sprawling urban development due to the low density and the prominence of large, single-family detached housing. Yang et al. (2015), meanwhile, obtained the result that a $1 \%$ increase in the built-up area will contribute to a $0.08 \%$ increase per capita in the $\mathrm{CO}_{2}$ emissions of the transportation sector. Especially when public transportation is limited and there is a spatial mismatch in the dispersed areas of the city, this will lead to increasing use of motor vehicles rather than sustainable travel modes such as public transportation, cycling, and walking. They noted that a polycentric structure, alternatively, can reduce commuting distance through the establishment of commercial, and entertainment subcenters (Lee and Lee, 2014). They used several measurements to create a polycentricity index: subcenters' share of center employment, the number of subcenters, the slope of the rank-size distribution, and the primacy and commuter shed ratio.

Several studies have sought to characterize the causal connection among shorter average commute time, polycentricity, and carbon emissions (Crane and Chatman, 2002; Meijers and Burger, 2010; Gordon and Lee, 2015). In the United States, the use of private cars in medium and large cities tends to supersede transit use due to the lack of convenient public transport station design and extensive coverage of route arrangements. As a result, for mitigating the carbon emissions, the public transportation networks should be highly compatible with polycentric urban area. Furthermore, they found policy strategies such as transit subsidies to greatly reduce the VMT (by nearly 46\%) and transportation-related $\mathrm{CO}_{2}$ emissions (by 18\%). Meanwhile, Bereitschaft and Debbage (2013) showed that the iregular boundaries with highly complex characteristics in the less compact urban landscapes commonly found in the dispersed city increase the number of cars and the duration of car travel times. In their experiment, they found that the annual PM2.5 emissions would increase by 3055 tons (12.4\%) as a result of a standard increase in urban shape complexity. In another study, Barla et al. (2011) proposed polycentric urban development to help reduce the level of emission, with their results demonstrating that a $2.7 \%$ curb in emission would result from a $10 \%$ reduction in commuting time.

\subsection{Compact City}

Opposite to the form of urban sprawl, compact city has since the 1990s been the consensus choice among researchers for promoting energy-efficiency and reducing pollution, as it encourages walking, cycling, and public transit use within the city (Abdullahi et al., 2015; Lee et al., 2015; Chang and Chen, 2016). Several compact city indicators have been developed, such as density, land use, trip distance, and availability of public 


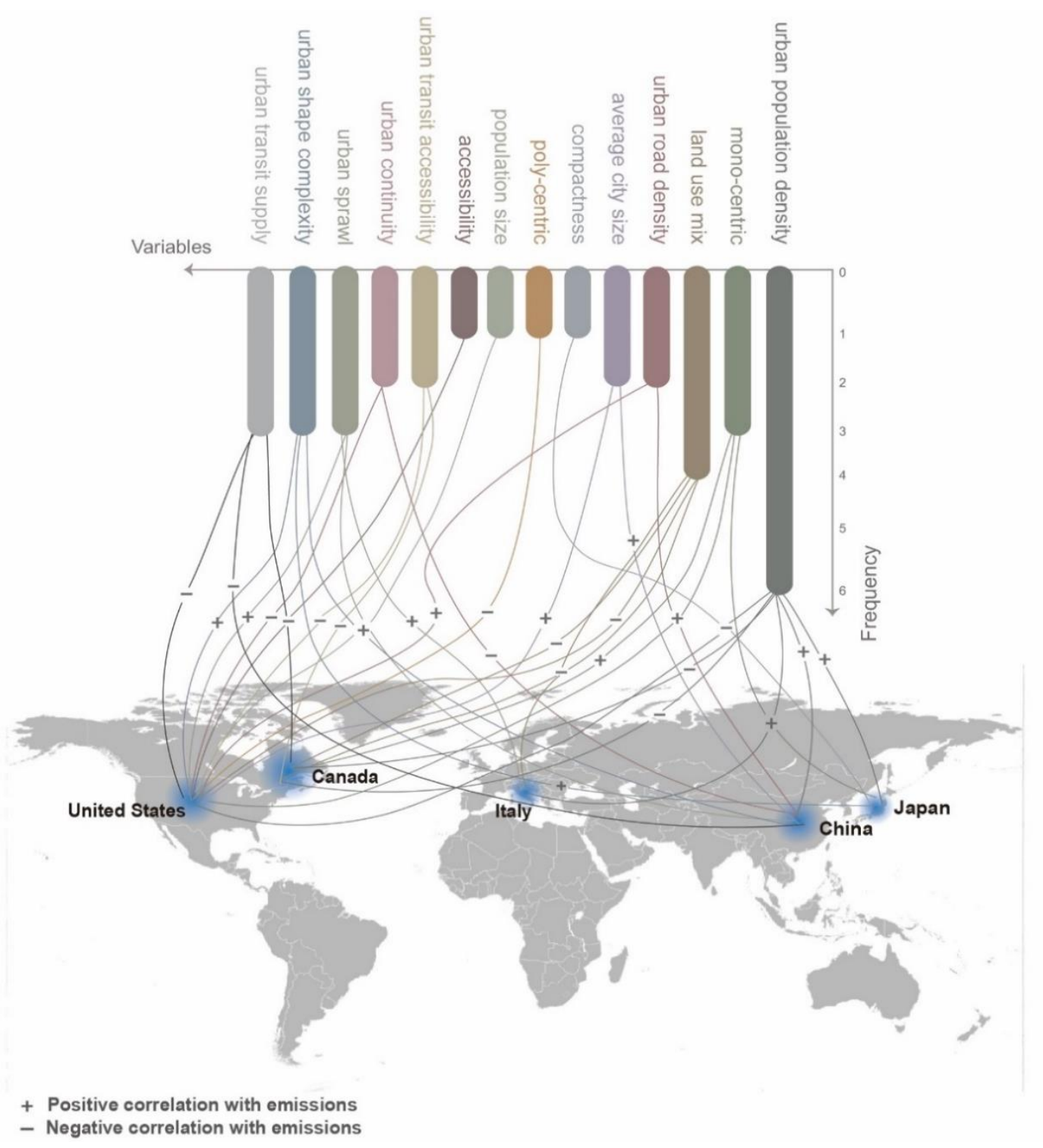

Figure 3. Correlations between variables in urban form and emissions in published studies.

transport services (OECD, 2012; Lee et al., 2015; Mizutani et al., 2015; Lee and Lim, 2018). When considering carbon emission in the private transport sector, many scholars have connected the indicators of compact city development with commuting behaviour and analyzed their relationships. Fang et al. (2015), for instance, demonstrated that travel distances can be reduced in a more compact city through the use of private vehicles, since the time and distance of commuting will be increaseed along with the decreasing degree of compactness associated with intricate and irregular boundaries. They also noted that the efficiency of city operation and urban land use intensity have positive correlations with the degree of compactness. They considered that, for a fast-growing city, the compact and continuous form is favorable for mitigating $\mathrm{CO}_{2}$ emissions once an optimum degree of compactness and matching public service system investment are achieved; otherwise, problems such as overcrowding will have a detrimental environmental effect. Liu and Shen (2011), meanwhile, in a study of U.S. cities, found that the choice of compact cars and non-motorized travel modes would increase in a denser city area. The compact car is a vehicle size class which is predominantly used than other vehicle classes in North America. It has better gas mileage than larger vehicles and thus reduces fuel consumption. From the perspective of spatial structure, the compact city emphasizes central development rather than a polycentric urban spatial structure (Gordon and Richardson, 1997).

Lee and Lee (2014) derived a centrality index based on the central business district's population share, area-based centrality index ratio of weighted to unweighted average distance, and population density gradient. They argued that population density can serve as a catch-all variable to represent compact urban form. The results of their multilevel SEM demonstrated a re- 
duction in $\mathrm{CO}_{2}$ emission from household travel and energy consumption by $48 \%$ and $35 \%$, respectively, relative to population-weighted density. As Bereitschaft and Debbage (2013) have asserted, compared with the tree-lined suburb, a compact area with denser population, convenient transportation, low per capita car ownership, and shorter distances to pedestrian and cycling destinations will have far lower carbon emissions. In terms of the $\mathrm{CO}_{2}$ emissions from the passenger transport sector, Makido et al. (2012) have suggested that regular shape and compact density of urban settlements could result in lower per capita emissions. However they noted that residential emissions can increase along with excessive density and monocentric urban development. Hankey and Marshall (2010), meanwhile, referenced three scenarios of urban development for the purpose of predicting future GHG emissions. Looking at these scenarios, per capita VKT was found to increase in the Constant Density mode and Suburban Nation mode but decrease in the Complete Infill mode. They predicted that the emissions in the Complete Infill mode in 2020 would see an $18 \%$ decrease compared to the year 2000, while the emissions in 2020 in the Suburban mode would see a $17 \%$ increase compared to 2000 . However, Marshall et al. (2005) considered that if the density elasticity magnitude is minimal or if the standards for vehicle emission system are low, compact cities may actually see worse air pollution than a conventional compact urban mode. Indeed, factors that reduce the average vehicle speed through intensive congestion, whether in low- or high-density cities, may worsen emissions and individual exposures to the vehicle pollutants. Furthermore, because of the density of compact cities, the exposure to air pollutants such as PM may also increase. In order to enhance the function of compact development in mitigating emissions, then, corresponding improvements in fuel and vehicle technologies should be pursued (Hankey and Marshall, 2010; Yao et al., 2020).

\section{Variables in Urban Form that Affect Household Vehicle GHG Emissions}

A variety of variables have been introduced to study the relationship between urban form and vehicle emissions (Figure 3 ). The size of the blue circle on the world map in the figure represents the amount of current research activity. It can be clearly seen from the figure that relatively little research in this area is underway in developing countries. This section will mainly analyze the essential variables based on the frequency of their appearance in previous studies.

\subsection{Density -A Tool to Analyze Social and Physical Qualities of Urban Environments}

Density as a concept in urban development was introduced in the $19^{\text {th }}$ century as a way of diagnosing and analyzing sprawling and overcrowded cities. The focus of studies in urban density then shifted from city development and migration to quantitative and qualitative analyses of the social and physical qualities of urban environments for the purpose of encouraging sustainability and vital human interaction in urban environments (Berghauser Pont and Haupt, 2009). Yang et al. (2015), for in- stance, employed urban population density and urban road density as the key variables in examining the relationship between density and $\mathrm{CO}_{2}$ emissions in China. They found that a $1 \%$ increase in urban population density and urban road density would result in $0.22 \%$ and $0.16 \%$ increases in per capita $\mathrm{CO}_{2}$ emissions, respectively. Studies of urban area in the United States have shown similar results in terms of road density. For instance, Su (2010) found that VMT increases along with incremental road density, while more frequently travelled and longer distances result in less burdensome and less timeconsuming travel in the United States. This suggests that simply complicated road density may actually result in more travel time and may increase per capita GHG emissions. In a similar study, Liu and Shen (2011) selected population density at the block group level from NHTS data to represent urban density in their analysis. They found that population density has indirect negative effects on VMT through intermediate variables such as vehicle speed, particularly the relationship between onroad vehicle emissions and changes in vehicle speed and engine load when driving conditions change. Emissions of $\mathrm{CO}$ and $\mathrm{NO}_{\mathrm{x}}$ have also been proven to have significant positive correlations with vehicle speed (Kean et al., 2003).

When looking at the direct effects, density can have a positive influence on walking mode choice, meaning that people in a denser area are more likely to prefer walking as a travel mode choice than are people in a less dense area. Residents of higher density neighbourhoods are also more likely to have smaller and more fuel-efficient vehicles. These indicated that the per capita $\mathrm{CO}_{2}$ emissions will be lower in a denser area. Lee and Lee (2014) used a population-weighted density as an alternative to conventional population density measurement to better capture density at a block group level. Their results showed the relatively prominent effects of density on household $\mathrm{CO}_{2}$ emissions. Under the same conditions, if all the direct and indirect elastic factors are combined, they found that the populationweighted density increases by $10 \%$, and the $\mathrm{CO}_{2}$ emissions generated by travel are reduced by $4.8 \%$ correspondingly. They proposed two possible explanations of this result. First, highdensity developments can provide more alternative transporttation modes and reduce the distance between different destinations, thus mitigating household VMT. Second, the passenger load of public transit is higher in high-density communities, and this increases carbon efficiency per passenger mile. Regarding population density, Zahabi et al. (2012) have argued that calculating the approximate population in each grid cell based on land use data (such as data from Desktop Mapping Technologies Inc., for example) can be an accurate method for allocating population. Their study in Montréal tried to figure out the relationship between transportation GHG emissions and urban form. Based on the fact that the Montréal region has a slightly higher population density and larger transit load than some U.S. cities, the results found that a $10 \%$ increase in population density would result in a $2.49 \%$ mitigation of household GHG, a finding seemingly more intuitive than those of previous North American studies. Bereitschaft and Debbage (2013), meanwhile, applied four system indices to represent urban sprawl level, population density being one of most the impor- 
tant measurements among four of them. Having conducted a regression test, they found that the level of population density also has a significant positive relationship with ozone concentration. In terms of the $\mathrm{CO}_{2}$ emissions from on-road sources, residential density was the only variable in urban form in their study which was shown to have a significant impact. With the same standard increase in residential density, they found that there would be a $22 \%$ reduction in $\mathrm{CO}_{2}$ emissions from on-road sources.

As an improvement upon the simple average population density metric used in other studies to capture population concentration, Makido et al. (2012) have argued that spatial determinants such as $\mathrm{CI}$ and $\mathrm{BCI}$ can be used to explain urban density in terms of distinguished patterns of settlement. They concluded that well-organized settlements with higher populations can reduce emissions in general, while massive density and mono-centric urban settlement could aggravate the residential emissions as well. As a possible explanation, they pointed to the compromising with the flexibility of building design principles in compact settlements. Zahabi et al. (2012) examined the case of Québec City and found that the average residential densities (people $/ \mathrm{km}^{2}$ ) in the center, the old suburbs, the new suburbs, and the periphery in as of 2011 were 4351, 2082, 1307, and 506, respectively. Accordingly, compared with the travel emission in the center, the emission in the old suburbs was found to be $19 \%$ higher, in the new suburbs $27 \%$ higher, and in the periphery $70 \%$ higher.

To provide insights into the expansion of road networks in the city over time, Hankey and Marshall (2010) introduced the Linear Population Density (LPD) as one variable of urban form to measure the number of people along a transect of an urban area. They then predicted the VKT based on the average population density in one urban area from transportation data. In the most-dense city considered in their study, Miami, where the population density is $2480 \mathrm{~km}^{-2}$, they predicted the VKT to be $30.9 \mathrm{~km} \mathrm{day}^{-1}$ person $^{-1}$. In the least-dense city under study, Kansas City, the density is $530 \mathrm{~km}^{-2}$ and accordingly they predicted the VKT to be $46.7 \mathrm{~km}^{\text {day }}{ }^{-1}$ person $^{-1}$.

\subsection{Mono-Centric-A Single and Prespecified Center with Production Activities}

With regard to monocentricity, one assumption that has been widely adopted within the field of "New Urban Economics" is that any given city has a single center which is the focal point of production activities. It is also called the central business district (CBD) which has a fixed size and provides places of employment for the entire population. In terms of patterns of urban sprawl in the classical monocentric-city model, there are three land-use patterns: leapfrog development, scattered development, and mixed development (Mills, 1981). Radial discontinuity is a notable characteristic of leapfrog development while the other two forms feature circumferential discontinuity (Fujita and Ogawa, 1982). Boarnet (1994) noted that, in the case of the monocentric urban model, there are important links between transportation access and the structure of the city. Furthermore, as noted by Veneri (2010), the spatial characteristics of urban areas, such as degree of polycentricity and or of urban configurations, can affect the externalities of commuting. Makido et al. (2012) developed a Buffer Compactness Index (BCI) to determine the distance between the central business area and surrounding areas and the density at various distances from the city center. This index was based on the percentage of urban area in separate ring buffers defined by $1 \mathrm{~km}$ intervals from the city center toward the exterior. Among the various results of their stepwise regression analysis of spatial metrics, BCI was the only positive correlative variable in increasing residential emissions per capita, which means that highly monocentric urban settlement likely increases residential emissions. Similarly, Cirilli and Veneri (2014) measured urban form in an urban area in Italy from intensity-based and spatial structure-based perspectives, estimating the level of urban mono-centricity by comparing the share of intensive employment in the central municipality. Compared with the polycentric development model, they noted, the monocentric model may entail less accessible amenities, especially in large urban areas, but either model may have high compactness. They concluded that, in large urban areas, the degree of mono-centricity is closely associated with GHG emissions. Bereitschaft and Debbage (2013), meanwhile, defined the degree of centricity in a city in terms of the proximity of housing and jobs for citizens to the CBD area. They found that the degree of centricity had a significant negative correlation with nonpoint source emissions.

\subsection{Urban Sprawl-Major Source of Environmental Problems}

One of the major environmental issues worldwide is urban sprawl, which is associated with consumption of agricultural and forested land, decreases in natural habitats and biodiversity, and progressive air pollution (Cai et al., 2020). Furthermore, the locations of households and businesses within cities will affect levels of GHG emissions and land consumption in urban structures (Legras and Cavailhès, 2016). As mentioned above, Fang et al. (2015) reviewed existing indices available in the literature and applied spatial metrics based on remote sensing data on land-use and land-cover. Tsai (2005) distinguished compact city and sprawled city by using quantitative methods with four metropolitan-form variables, namely, metropolitan size, density, degree of equal distribution, and degree of clustering. Matsuhashi and Ariga (2016) compared two population distribution scenarios for Sagamihara, Japan, in 2030, one a compact distribution and the other a dispersed distribution. The city was plotted using large-population meshes of cells representing the compact distribution scenario and the dispersed distribution scenario. In other words, in the compact scenario the city will have a denser urban structure than the dispersed scenario. According to their forecast results, under the condition of compact distribution, the annual per capita $\mathrm{CO}_{2}$ emission level associated with passenger cars decreases with time, while under the condition of dispersed distribution, annual per capita passenger car $\mathrm{CO}_{2}$ emissions increase with time. The annual per capita passenger car $\mathrm{CO}_{2}$ emissions generated in the dispersed distribution scenario was estimated to be roughly $10 \%$ higher than the estimate of the same in the compact 
distribution scenario.

Travisi et al. (2010) analyzed the relationship between urban sprawl and commuting in Italy using multivariate crosssection regression analysis and Causal Path Analysis, and their empirical results confirmed that urban sprawl is accompanied by intensive travel and associated environmental effects. They also noted that sprawl is one of the explanatory variables for the dependent variable "mobility impact index". The level of sprawl was controlled by three factors in Travisi's work: DENSITY (urban density was estimated as the gross density of cities), MIXITE (the ratio between jobs and residents) and RURAL (the rate of agricultural areas in the built environment). Car ownership by urban residents and urban sprawl itself have also been found to affect one another in a tradeoff relationship - urban expansion has exacerbated residents' dependence on car travel, while the growing dependence on cars has, in turn, contributed to urban sprawl (Dulal et al., 2011).

The Smart Growth America (SGA) composite urban sprawl index has been widely used in research studies for observing the relationships among transportation impact, air pollution, climate change, and the level of urban sprawl (Ewing et al., 2002; Ewing et al., 2003; Stone Jr, 2008; Stone et al., 2010). The SGA index is composed of four components: residential density, street connectedness, regional centeredness, and landuse mix. Other than residential density, the components are also multipart index measures. The SGA index is an inverted scale, which means high scores represent more compactness while lower scores correspond to more sprawl (Schweitzer and Zhou, 2010).

\subsection{Urban Shape Complexity - Physical Features of Urban Landscapes}

Complexity is one of the spatial metrics employed to represent the physical features of urban landscapes. The area weighted mean shape index (AWMSI) and the aera weighted mean patch fractal dimension (AWMPFD) were applied by Huang et al. (2007), Makido et al. (2012), and Fang et al. (2015) to measure the irregularity of the patch shape, representing complexity index. About AWMSI and AWMPFD, Fang et al. (2015) added another index, the landscape shape index, to measure the perimeter-to-area ratio of a given landscape as a way of describing urban shape complexity. AWMSI, it should be noted, represents the shape irregularity of the landscape structure by measuring the patches, while AWMPFD describes the raggedness of the urban boundary and implies an unplanned growth urban area. It is derived from the fractal dimension using remote sensing, which is a suitable method for measuring real-world cities (Longley and Mesev, 2000). Their results mentioned above in this paragraph showed different relationships among urban complexity, residential $\mathrm{CO}_{2}$ emissions, and transport $\mathrm{CO}_{2}$ emissions. The effect of urban complexity on residential $\mathrm{CO}_{2}$ emissions was found to be negligible (Makido et al., 2012), while on-transport $\mathrm{CO}_{2}$ emissions was significant. Residents who lived in higher-regularity and higherdensity settlements tended to produce less per capita transport emissions, as their commuting activities were less influenced by the irregular edges of the cities. Nevertheless, compared with other factors, the role of complexity in reducing $\mathrm{CO}_{2}$ emissions has been found to be relatively insignificant Makido et al. (2012).

In the research of Fang et al. (2015), a high value of shape complexity implies a more irregular urban form, as indicated by increased commuting time and distance. Thus, increased $\mathrm{CO}_{2}$ emissions is closely associated with urban shape complexity in their research. Based on the notion of perimeter-to-area ratio, it should be noted, shape complexity can be understood as the "jaggedness" of the urban boundary. Bereitschaft and Debbage (2013) used principal component analysis (PCA) to categorize the multiple landscape metrics for measuring the shape complexity of urban development. As they noted, there are total four landscape metrics derived from multiple satellitebased metrics for measuring urban complexity: area-weighted mean shape index, landscape shape index, area-weighted mean patch fractal dimension, and edge density. They found that, after running a regression model, an increase of one standard deviation in urban shape complexity will result in an $8.7 \%$ increase in $\mathrm{NO}_{\mathrm{x}}$ emissions and a $12.4 \%$ increase in PM2.5 emissions. The reason for this is that highly convoluted landscapes will lead to a rise in the number and duration of automotive trips.

\subsection{Continuity-A Method to Measure the Uninterrupted Level in Urban Areas}

Continuity refers to the extent to which land is developed in an uninterrupted manner in urban contexts. Continuity provides a way to measure the size of the development and the distance between the developed metropolitan area and any discontinuous areas (Tsai, 2005). It also provides a way to measure the level of polymerization or fragmentation between patches, i.e., "leapfrog" development (Bereitschaft and Debbage, 2013). Galster et al. (2001) defined continuity as a function of density, and they assessed the level of continuity in urban development by observing the number of the housing units and places of employment. The quantitative operationalization they proposed is divided into two steps. The first step is to determine whether a given cell in a grid of 1.5-mile square cells contains over 10 housing units or over 50 employees. The second step is to calculate the proportion of all such cells in the grid as way of measuring continuity (Galster et al., 2001). Fang et al. (2015), meanwhile, used COHESION (the connectedness of urban areas), AI, and CONTIG (the aggregation of urban areas) to represent the degree of urban continuity, which contributes to the connection and aggregation of a city. The average commuting distance in a fragmented and interspersed developed area, they noted, will be much farther than that in high aggregation and highly connected areas. They also found that urban expansion with a pattern of high connectedness is beneficial in terms of curbing $\mathrm{CO}_{2}$ emissions. In a similar study, Bereitschaft and Debbage (2013) used urban continuity to represent the degree of fragmentation of an urban landscape, where an area with highly integrated development is described as having high urban continuity. In such an area, they found, residents will 
typically have shorter automotive trips and thus less carbon emissions from nonpoint sources due to there being less open space separating different parts of the city. In their study, they found that one standard deviation increased in urban continuity contributed to an 8,647 ton (or 9\%) reduction in annual VOC emissions.

\subsection{Land Use Mix-Reducing the Distance between Origin and Destination}

Land use mix within a neighbourhood is important in terms of its effect on residents' lifestyle, where the key advantage of mixed use is that it brings various origins and destinations closer together. The location of destinations within an acceptable distance can encourage residents to walk or bicycle instead of driving, thus reducing vehicle dependence (Duncan et al., 2010). In terms of assessing the impacts of land use mix on travel, the land use mix index evaluates the balance between distance from workplace to residence and the diverse functions such as recreational function and commercial function within the area under study. Liu and Shen (2011), for instance, considered land use mix as one of the variables in urban form. They captured the even level of square footage of various land uses such as commercial, residential, and official floor area located within a given household's 1-mile buffer distribution. The results of their study were found to be consistent with the finding of a previous study in which land use mix has a modest effect on the elasticity of VMT (Ewing and Cervero, 2001). Stone et al. (2010) and Bereitschaft and Debbage (2013) both applied three elements, the ratio of jobs to population, the diversity of land uses, and the accessibility of residential uses to nonresidential uses, at the level of the transportation analysis zone and within a 1-mile radius to represent land-use mix attribute. Zahabi et al. (2012), meanwhile, combined with the nine-cell grid approach, defined land use mix in terms of an entropy index with residential, commercial, institutional and governmental, resource and industrial, and parks and recreation. They found that the promotion of land use mix plays a negligible role in reducing the carbon footprint of daily travel. Hankey and Marshall (2010) noted with respect to the U.S. context that encouraging policy measures such as zoning for mixed use is a common strategy for compact growth, as there are inherent connections among energy, environment, and land-use patterns. Cervero (1988) considered that mixed land-use planning policies could serve to mitigate energy consumption in the transportation system as an alternative strategy to trip chaining and curtailment of trip length. In another study, based on a survey conducted in the San Francisco Bay Area, Cervero and Duncan (2006) examined the degree to which job accessibility is associated with reduced work travel and how closely retail and service accessibility is correlated with miles and hours logged travelling to shopping destinations. They found that improving the jobs to housing land-use mix strategy can reduce travel. Ewing and Cervero (2010), meanwhile, conducted a metaanalysis of the literature on built environment and travel. They concluded that land use diversity can strongly influence the choice to walk and is a secondary factor for bus and train use. Similarly, other researchers have noted that, in order to reduce drive-alone travel, communities are increasingly seeking mixed land use planning strategies to mitigate GHG emissions from vehicles (Srinivasan, 2002; Krizek, 2003).

\subsection{Accessibility-Describing the Performance of Road Network}

Accessibility is one of the fundamental factors in shaping the dimensional organization of economic activities and contributing to traffic flow. Indeed, controlling the level of accessibility with regards to transport infrastructure endowment is critical in analyzing the relationship between spatial structure and the external effects of commuting (Cirilli and Veneri, 2014). Travisi et al. (2010) considered accessibility as one of the prominent factors in characterizing the relationship between travel impacts and the quality of public transport services. They used the variable, SHAREPUB, which captures the market share of public transport calculated with the proportion of all trips made by public transport used as the metric to represent accessibility. Kitamura et al. (2001) studied the effect of the level of accessibility on long-term and short-term travel behaviour. The prism-based measures used in their research showed that people might easily obtain opportunities to participate in activities in urban areas. In a similar manner, McConville et al. (2011) analyzed the accessibility of nonresidential land use and its influence on the choice of walking as a mode of transportation. They measured the street distance from the participant's home to the closest instance of various land uses such as physical activity uses and social uses. Liu and Shen (2011) determined accessibility based on the number of jobs within a given zone, the travel time from zone to zone, and the travel flow matrices. In the initial regression outcomes, when controlling the other urban form variables and household characteristics, accessibility was found to be the most significant factor influencing household VMT. Zahabi et al. (2012) found, based on the grid approach, that higher transit accessibility is correlated with public transit stops being closer to the cell centroid (i.e., a smaller headway). They calculated this by aggregating each line's closest stops to each cell, and found that a $10 \%$ increase in public transit accessibility is associated with a $5.17 \%$ decrease in household GHG emissions. They thus considered the promotion of transit accessibility to be just as important as improvements in the fuel-efficiency of vehicles in reducing GHG emissions.

\section{Opportunities in Urban Form Planning for the Mitigation of Household Vehicle GHG Emissions}

Based on the above review, the rational allocation of land, as well as the relationship between urban form and intelligent development and low-carbon transportation (and the associated opportunities), in various jurisdictions around the world can be summarized in terms of five notable aspects.

The first is the relationship between the model of urban space utilization and low-carbon development. The utilization pattern of urban space encompasses urban density and land use mix, where the density of a city can be represented as population density or employment density. Rises in the degree of 
urban density and mixed function can effectively reduce the per capita car usage, thereby reducing fuel consumption and GHG emissions. It is thus necessary to strengthen mixed land use and diversified development, and to move away from the practice of zoning for a single function. It can help mitigate unnecessary traffic demand from the source, including reducing the number of trips and shortening the distance of travel, while simultaneously strengthening access to employment and services, and creating employment, leisure, and shopping opportunities within an acceptable proximity. This can significantly reduce the demand for travel, enabling people to reach work and shopping locations within a shorter time and lesser distance and thus reduce energy consumption and carbon emissions.

The second aspect is the relationship between urban spatial form and low-carbon development. The impact of urban space morphology on carbon emissions is mainly reflected in the continuity of urban space and the dispersion of centers. Continuous urban space helps improve accessibility between various urban activities, thereby reducing travel distance and keeping carbon emissions in check. A decentralized trend in development and construction of urban land, even in the form of leapfrog or enclave, is not conducive to the realization of low-carbon goals. The polycentric development model not only reduces travel distance, but also makes travel more balanced, controls urban sprawl, reduces the traffic congestion caused by excessive concentration in the center, and reduces the pollution and carbon emissions from traffic. At the same time, it can alleviate the strong heat island effect caused by the excessive concentration in a single center and thereby reduce the energy consumption required for space-cooling in the built environment.

The third aspect is the relationship between urban transportation mode and low-carbon development, specifically the changes in transportation structure as a result of low-carbon development. Based on the scale of the urban area, the development of urban public transportation and non-motorized travel in the transportation system should be supported, and the integrated development and operation of the public transportation system should be emphasized to make the regional transportation network adaptable to the spatial layout. Based on the scale of the neighbourhood area, the accessibility of walking and public transportation systems should be considered in order to reduce the dependence of residents on private cars. Increasing the density of urban public transport coverage, guiding public transport as a priority, designing optimal transfer plans, shortening bus travel time, and improving bus travel efficiency are all strategies that can enhance the attractiveness of public transport travel to residents. From the perspective of urban form and street design, replacing the development of major roads and street blocks with the development of small blocks and pedestrian paths can play an important role in encouraging low-carbon travel.

The fourth aspect is the promotion of energy-saving and energy-efficient vehicles, where governments can promote the use of energy-saving and low-carbon vehicles through policy measures such as financial incentives and taxation. Not only can this reduce the dependence on fossil energy, but it can also reduce the emission of automobile exhaust.

The fifth aspect is the promotion of low-carbon development through urban smart management. The $\mathrm{CO}_{2}$ emitted by vehicles in congested traffic is much more than that during high-speed driving. Intelligent transport systems (ITS) refers to a system designed to integrate residents, road networks and vehicles in order to resolve traffic problems such as traffic congestion, traffic accidents and environmental degradation. In this context, ITS, which is widely-used in Japan, can improve road use efficiency and thereby reduce congestion. The intelligent transportation technology, vehicle information and communication system (VICS), meanwhile, can alleviate traffic congestion by increasing vehicle speed, thereby improving fuel efficiency and reducing emissions. The intelligentization and informatization of transportation represent an important trend influencing future urban development patterns. Moreover, the combination of intelligent information technology and low-carbon technology, as well as urban scientific management, and the development and application of technologies such as big data can be used to promote smart energy management. Furthermore, the development and integration of technologies and management systems such as transportation, building energy efficiency, and circular economy will play a strong role in promoting the integration of resource allocation and the optimization of low-carbon technologies in urban settings.

\section{Conclusions}

The extent to which, and the manner in which, urban form and land-use planning strategies support sustainable transportation and the mitigation of GHG emissions from vehicles are contingent upon the effective coordination of different institutions and on strong political support. Given that a considerable amount of time is required to improve municipal infrastructure such as public transit systems, the effective and efficient use of land might have a limited influence on the mitigation of GHG emissions in the short term, but it will pay off in the long run. While car ownership and car dependence will gradually increase with a growing standard of living in the absence of policy interventions or robust public transit infrastructure, carefully designed urban development patterns and efficient public transport will effectively reduce traffic volume and the use of private cars.

This paper reviews the data types and analysis methods that are most widely used in studies on the impact of urban form on private vehicle GHG emissions. To study the change of carbon emissions caused by the evolution of urban form in a period of time, panel data type is a good choice for capturing dynamic changes. When dealing with the impact of urban form index on traffic emission and human travel behaviour, it is possible to characterize the relationship between multiple causes and results and to identify variables that cannot be observed directly. While traditional statistical analysis methods cannot properly handle these latent variables, SEM can effectively replace multiple regression, path analysis, factor analysis, and covariance analysis to clearly analyze the effects of individual indicators on latent variables and the interactions between indi- 
vidual indicators by calculating direct effects, indirect effects, and total effects (Kaplan, 1995). This paper also demonstrates the scale and the manner in which the $\mathrm{CO}_{2}$ emissions by the transportation sector are calculated, determining the difference in household vehicle GHG emissions between the dispersed city and the compact city accordingly. Seven high-frequency variables in urban form identified in the literature - density, mono-centricity, urban sprawl, urban shape complexity, continuity, land use mix, and accessibility - are compared in terms of how they define, and analyze the impact of, urban development patterns on travel behaviour and vehicle emissions. Finally, based on the rational allocation of land, suggestions and opportunities in urban form and intelligent development for low-carbon transportation are summarized from urban space utilization, urban spatial morphology, urban transportation mode, energy-saving and energy-efficient vehicles, and urban smart management perspectives.

Acknowledgments. This research was supported by the National Key Research and Development Plan (2016YFA0601502), the Natural Sciences and Engineering Research Council of Canada. The authors are also thankful for the suggestions from Jonathan Tomalty.

\section{References}

Abdullahi, S., Pradhan, B., Mansor, S. and Shariff, A.R.M. (2015). GIS-based modeling for the spatial measurement and evaluation of mixed land use development for a compact city. GIScience and Remote Sensing, 52(1), 18-39. https://doi.org/10.1080/15481603. 2014.993854

Al-mulali, U. (2012). Factors affecting $\mathrm{CO}_{2}$ emission in the Middle East: A panel data analysis. Energy, 44(1), 564-569. https://doi org/10.1016/j.energy.2012.05.045

Anderson, W.P., Kanaroglou, P.S. and Miller, E.J. (1996). Urban form, energy and the environment: a review of issues, evidence and policy. Urban Studies, 33(1), 7-35. https://doi.org/10.1080/004209896500 12095

Balsas, C.J.L. (2000). City center revitalization in Portugal: Lessons from two medium size cities. Cities, 17(1), 19-31. https://doi.org /10.1016/S0264-2751(99)00049-9

Barla, P., Miranda-Moreno, L.F. and Lee-Gosselin, M. (2011). Urban travel $\mathrm{CO}_{2}$ emissions and land use: A case study for Quebec City. Transportation Research Part D: Transport and Environment, 16(6), 423-428. https://doi.org/10.1016/j.trd.2011.03.005

Bechle, M.J., Millet, D.B. and Marshall, J.D. (2011). Effects of income and urban form on urban $\mathrm{NO}_{2}$ : Global evidence from satellites. Environmental Science and Technology, 45(11), 4914-4919. https://doi.org/10.1021/es103866b

Bereitschaft, B. and Debbage, K. (2013). Urban form, air pollution, and $\mathrm{CO}_{2}$ emissions in large US metropolitan areas. The Professional Geographer, 65(4), 612-635. https://doi.org/10.1080/00330124. 2013.799991

Berghauser Pont, M.Y. and Haupt, P.A. 2009. Space, density and urban form. Doctoral thesis, Delft University of Technology.

Boarnet, M.G. (1994). The monocentric model and employment location. Journal of Urban Economics, 36(1), 79-97. https://doi.or $\mathrm{g} / 10.1006 /$ juec.1994.1027

Cai, M., An, C. and Guy, C. (2020). Assessment of Soil and Water Conservation Practices in the Loess Hilly Region Using a Coupled Rainfall-Runoff-Erosion Model. Sustainability, 12(3), 934. https:// doi.org/10.3390/su12030934

Carruthers, J.I. (2003). Growth at the fringe: The influence of political fragmentation in United States metropolitan areas. Papers in Regional Science, 82(4), 475-499. https://doi.org/10.1007/s10110003-0148-0

Cervero, R. (1988). Land-use mixing and suburban mobility. Berkeley, CA: UC Berkeley: University of California Transportation Center.

Cervero, R. and Duncan, M. (2006). 'Which Reduces Vehicle Travel More: Jobs-Housing Balance or Retail-Housing Mixing? Journal of the American Planning Association, 72(4), 475-490. https://doi. org/10.1080/01944360608976767

Chang, H.S. and Chen, T. (2016). Examine sustainable urban space based on compact city concept. Global Journal of Human-Social Science: B Geography, Geo-Sciences, Environmental Science and Disaster Management, 16(4), 2-12.

Chen, Z., An, C., Fang, H., Zhang, Y., Zhou, Z., Zhou, Y. and Zhao, S. (2020). Assessment of regional greenhouse gas emission from beef cattle production: A case study of Saskatchewan in Canada. Journal of Environmental Management, 264, 110443. https://doi.org/10. 1016/j.jenvman.2020.110443

Cirilli, A. and Veneri, P. (2014). Spatial structure and carbon dioxide $\left(\mathrm{CO}_{2}\right)$ emissions due to commuting: An analysis of Italian urban areas. Regional Studies, 48(12), 1993-2005. https://doi.org/10.1080 /00343404.2013.827333

Clark, L.P., Millet, D.B. and Marshall, J.D. (2011). Air quality and urban form in US urban areas: evidence from regulatory monitors. Environmental Science and Technology, 45(16), 7028-7035. https:// doi.org/10.1021/es2006786

Crane, R. and Chatman, D.G. (2002). Traffic and Sprawl: Evidence from US Commuting from 1985-1997, Los Angeles, CA, University of Southern California.

Dulal, H.B., Brodnig, G. and Onoriose, C.G. (2011). Climate change mitigation in the transport sector through urban planning: A review. Habitat International, 35(3), 494-500. https://doi.org/10.1016/ j.habitatint.2011.02.001

Duncan, M.J., Winkler, E., Sugiyama, T., Cerin, E., Leslie, E. and Owen, N. (2010). Relationships of land use mix with walking for transport: do land uses and geographical scale matter? Journal of Urban Health, 87(5), 782-795. https://doi.org/10.1007/s11524-0109488-7

Ewing, R. and Cervero, R. (2001). Travel and the built environment: a synthesis. Transportation Research Record, 1780(1), 87-114. https: //doi.org/10.3141/1780-10

Ewing, R. and Cervero, R. (2010). Travel and the built environment: A meta-analysis. Journal of the American Planning Association, 76(3), 265-294. https://doi.org/10.1080/01944361003766766

Ewing, R., Pendall, R. and Chen, D. (2003). Measuring sprawl and its transportation impacts. Transportation Research Record, 1831(1), 175-183. https://doi.org/10.3141/1831-20

Ewing, R. and Rong, F. (2008). The impact of urban form on US residential energy use. Housing Policy Debate, 19(1), 1-30. https:// doi.org/10.1080/10511482.2008.9521624

Ewing, R.H., Pendall, R. and Chen, D.D. (2002). Measuring sprawl and its impact, Washington, DC, Smart Growth America

Fang, C., Wang, S. and Li, G. (2015). Changing urban forms and carbon dioxide emissions in China: A case study of 30 provincial capital cities. Applied Energy, 158, 519-531. https://doi.org/10.10 16/j.apenergy.2015.08.095

Fujita, M. and Ogawa, H. (1982). Multiple equilibria and structural transition of non-monocentric urban configurations. Regional Science and Urban Economics, 12(2), 161-196. https://doi.org /10.1016/0166-0462(82)90031-X

Galster, G., Hanson, R., Ratcliffe, M.R., Wolman, H., Coleman, S. and Freihage, J. (2001). Wrestling sprawl to the ground: defining and measuring an elusive concept. Housing Policy Debate, 12(4), 681717. https://doi.org/10.1080/10511482.2001.9521426

Glaeser, E.L. and Kahn, M.E. (2010). The greenness of cities: carbon dioxide emissions and urban development. Journal of Urban 
Economics, 67(3), 404-418. https://doi.org/10.1016/j.jue.2009.11. 006

Gordon, P. and Lee, B. (2015). Spatial structure and travel: Trends in commuting and non-commuting travels in US metropolitan areas. In Handbook on transport and development. Glos, UK: Edward Elgar Publishing.

Gordon, P. and Richardson, H.W. (1997). Are compact cities a desirable planning goal? Journal of the American Planning Association, 63(1), 95-106. https://doi.org/10.1080/019443697089 75727

Hankey, S. and Marshall, J.D. (2010). Impacts of urban form on future US passenger-vehicle greenhouse gas emissions. Energy Policy, 38(9), 4880-4887. https://doi.org/10.1016/j.enpol.2009.0 7.005

Hawkes, A. (2014). Long-run marginal $\mathrm{CO}_{2}$ emissions factors in national electricity systems. Applied Energy, 125, 197-205. https:// doi.org/10.1016/j.apenergy.2014.03.060

Hu, M.M. and Xia, B.C. (2020). Land-Use Variations in Regions with Rapid Economic Development - A Case Study in the Pearl River Delta. Journal of Environmental Informatics Letters, 3(1), 49-58. https://doi.org/10.3808/jeil.202000024

Huang, J., Lu, X.X. and Sellers, J.M. (2007). A global comparative analysis of urban form: Applying spatial metrics and remote sensing. Landscape and Urban Planning, 82(4), 184-197. https://doi.org/ 10.1016/j.landurbplan.2007.02.010

Ishii, S., Tabushi, S., Aramaki, T. and Hanaki, K. (2010). Impact of future urban form on the potential to reduce greenhouse gas emissions from residential, commercial and public buildings in Utsunomiya, Japan. Energy Policy, 38(9), 4888-4896. https://doi. org/10.1016/j.enpol.2009.08.022

Kaplan, D. (1995). Statistical power in structural equation modeling. Structural Equation Modeling: Concepts, Issues, and Applications, 100-117.

Kean, A.J., Harley, R.A. and Kendall, G.R. (2003). Effects of Vehicle Speed and Engine Load on Motor Vehicle Emissions. Environmental Science and Technology, 37(17), 3739-3746. https://doi. org/10.1021/es0263588

Kitamura, R., Akiyama, T., Yamamoto, T. and Golob, T.F. (2001). Accessibility in a metropolis: Toward a better understanding of land use and travel. Transportation Research Record, 1780(1), 64-75. https://doi.org/10.3141/1780-08

Krizek, K.J. (2003). Neighborhood services, trip purpose, and tourbased travel. Transportation, 30(4), 387-410. https://doi.org/10. 1023/A: 1024768007730

Lee, J., Kurisu, K., An, K. and Hanaki, K. (2015). Development of the compact city index and its application to Japanese cities. Urban Studies, 52(6), 1054-1070. https://doi.org/10.1177/0042098 0145 36786

Lee, J.H. and Lim, S. (2018). The selection of compact city policy instruments and their effects on energy consumption and greenhouse gas emissions in the transportation sector: The case of South Korea. Sustainable Cities and Society, 37, 116-124. https://doi. org/10.1016/j.scs.2017.11.006

Lee, S. and Lee, B. (2014). The influence of urban form on GHG emissions in the US household sector. Energy Policy, 68, 534-549. https://doi.org/10.1016/j.enpol.2014.01.024

Legras, S. and Cavailhès, J. (2016). Environmental performance of the urban form. Regional Science and Urban Economics, 59, 1-11. https://doi.org/10.1016/j.regsciurbeco.2016.03.002

Liu, C. and Shen, Q. (2011). An empirical analysis of the influence of urban form on household travel and energy consumption. Computers, Environment and Urban Systems, 35(5), 347-357. https://doi. org/10.1016/j.compenvurbsys.2011.05.006

Liu, Y., Chen, X. and Wang, H. (2020). Perspective for emission and control of nitrous gas in biological wastewater treatment. Journal of Environmental Informatics Letters, 2(2), 82-90 https://doi.org/10. 3808/jeil.201900020

Longley, P.A. and Mesev, V. (2000). On the measurement and genera- lisation of urban form. Environment and Planning A, 32(3), 473488. https://doi.org/10.1068/a3224

Makido, Y., Dhakal, S. and Yamagata, Y. (2012). Relationship between urban form and $\mathrm{CO}_{2}$ emissions: Evidence from fifty Japanese cities. Urban Climate, 2, 55-67. https://doi.org/10.1016/j.uclim.2012.10. 006

Marshall, J.D., McKone, T.E., Deakin, E. and Nazaroff, W.W. (2005). Inhalation of motor vehicle emissions: effects of urban population and land area. Atmospheric Environment, 39(2), 283-295. https://d oi.org/10.1016/j.atmosenv.2004.09.059

Matsuhashi, K. and Ariga, T. (2016). Estimation of passenger car $\mathrm{CO}_{2}$ emissions with urban population density scenarios for low carbon transportation in Japan. IATSS Research, 39(2), 117-120. https:// doi.org/10.1016/j.iatssr.2016.01.002

McConville, M.E., Rodriguez, D.A., Clifton, K., Cho, G. and Fleischhacker, S. (2011). Disaggregate land uses and walking. American Journal of Preventive Medicine, 40(1), 25-32. https://doi.org/10. 1016/j.amepre.2010.09.023

Meijers, E.J. and Burger, M.J. (2010). Spatial structure and productivity in US metropolitan areas. Environment and Planning A, 42(6), 1383-1402. https://doi.org/10.1068/a42151

Mills, D.E. (1981). Growth, speculation and sprawl in a monocentric city. Journal of Urban Economics, 10(2), 201-226. https://doi.o $\mathrm{rg} / 10.1016 / 0094-1190(81) 90015-2$

Mizutani, F., Nakayama, N. and Tanaka, T. (2015). An analysis of the effects of the compact city on economic activities in Japan. The Home of Regional Science in Europe. European Regional Science Association.

Muñiz, I., García López, M.À. and Calatayud, D. (2006). Sprawl: definición, causas y efectos. Department of Applied Economics at Universitat Autonoma of Barcelona, Working Papers.

OECD, G.G.S. (2012). Compact city policies: A comparative assessment. Paris: OECD Publishing. https://doi.org/10.1787/97892641 67865-en

Preacher, K.J., Zhang, Z. and Zyphur, M.J. (2011). Alternative methods for assessing mediation in multilevel data: The advantages of multilevel SEM. Structural Equation Modeling, 18(2), 161-182. https://doi.org/10.1080/10705511.2011.557329

Schweitzer, L. and Zhou, J. (2010). Neighborhood air quality, respiretory health, and vulnerable populations in compact and sprawled regions. Journal of the American Planning Association, 76(3), 363371. https://doi.org/10.1080/01944363.2010.486623

Song, P., Huang, G., An, C., Zhang, P., Chen, X. and Ren, S. (2019). Performance analysis and life cycle greenhouse gas emission assessment of an integrated gravitational-flow wastewater treatment system for rural areas. Environmental Science and Pollution Research, 26(25), 25883-25897. https://doi.org/10.1007/s11356-01905746-2

Srinivasan, S. (2002). Quantifying spatial characteristics of cities. Urban Studies, 39(11), 2005-2028. https://doi.org/10.1080/004209 8022000011335

Stone, B., Hess, J.J. and Frumkin, H. (2010). Urban form and extreme heat events: are sprawling cities more vulnerable to climate change than compact cities? Environmental Health Perspectives, 118(10), 1425-1428. https://doi.org/10.1289/ehp.09 01879

Stone Jr, B. (2008). Urban sprawl and air quality in large US cities. Journal of Environmental Management, 86(4), 688-698. https://doi. org/10.1016/j.jenvman.2006.12.034

Stone Jr, B. and Rodgers, M.O. (2001). Urban form and thermal efficiency: how the design of cities influences the urban heat island effect. American Planning Association. Journal of the American Planning Association, 67(2), 186. https://doi.org/10.1080/01944 360108976228

$\mathrm{Su}, \mathrm{Q}$. (2010). Travel demand in the US urban areas: A system dynamic panel data approach. Transportation Research Part A: Policy and Practice, 44(2), 110-117. https://doi.org/10.1016/j.tr a.2009.12.003 
Sun, W., An, C., Li, G. and Lv, Y. (2014). Applications of inexact programming methods to waste management under uncertainty: current status and future directions. Environmental Systems Research, 3(1), 15. https://doi.org/10.1186/s40068-014-0015-9

Travisi, C.M., Camagni, R. and Nijkamp, P. (2010). Impacts of urban sprawl and commuting: a modelling study for Italy. Journal of Transport Geography, 18(3), 382-392. https://doi.org/10.1016/j.jt rangeo.2009.08.008

Tsai, Y.H. (2005). Quantifying urban form: compactness versus sprawl. Urban Studies, 42(1), 141-161. https://doi.org/10.1080/0042098 042000309748

U.S. Energy Information Administration (2019). International energy outlook 2019. Washington, DC: U.S. Department of Energy.

Veneri, P. (2010). Urban polycentricity and the costs of commuting: Evidence from Italian metropolitan areas. Growth and Change, 41(3), 403-429. https://doi.org/10.1111/j.1468-2257.2010.00531.x

Wu, Q. and Xia, X. (2019). Response of Surface Water Quality in Urban and Non-urban Areas to Heavy Rainfall: Implications for the Impacts of Climate Change. Journal of Environmental Informatics Letters, 1(1), 27-36. https://doi.org/10.3808/jeil.201 900004

Yang, W., Li, T. and Cao, X. (2015). Examining the impacts of socio- economic factors, urban form and transportation development on $\mathrm{CO}_{2}$ emissions from transportation in China: a panel data analysis of China's provinces. Habitat International, 49, 212-220. https://doi. org/10.1016/j.habitatint.2015.05.030

Yao, Y., Huang, G., An, C., Chen, X., Zhang, P., Xin, X., Shen, J. and Agnew, J. (2020). Anaerobic digestion of livestock manure in cold regions: Technological advancements and global impacts. Renewable and Sustainable Energy Reviews, 119, 109494. https://doi.org/ 10.1016/j.rser.2019.109494

Zahabi, S.A.H., Miranda-Moreno, L., Patterson, Z., Barla, P. and Harding, C. (2012). Transportation greenhouse gas emissions and its relationship with urban form, transit accessibility and emerging green technologies: a Montreal case study. Procedia-Social and Behavioral Sciences, 54, 966-978. https://doi.org/10.1016/j.sbspro. 2012.09.812

Zhang, P., Huang, G., An, C., Fu, H., Gao, P., Yao, Y. and Chen, X. (2019). An integrated gravity-driven ecological bed for wastewater treatment in subtropical regions: process design, performance analysis, and greenhouse gas emissions assessment. Journal of Cleaner Production, 212, 1143-1153. https://doi.org/10.1016/j.jclepro.2018. 12.027 